\title{
Pharma influence widespread at medical schools: study
}

\section{$\mathrm{R}$}

ecent research has revealed widespread pharmaceutical influence and weak institutional safeguards in Canadian medical schools. But lecturers, medical students and ethicists are far from united on the extent to which relations with industry are acceptable and what role universities should play in preparing students to withstand influence.

A July 4 study in PLoS One ranked the rigour of Canadian medical schools' 2011 conflict-of-interest policies (PLoS One 2013;8:e68633). A simple conflict of interest would be gifts, where drug companies provide pens, prescription pads or lunches, while a more complex conflict of interest would be ghostwriting, where faculty members sign on as authors of studies conducted and written by pharmaceutical companies.

Only 4 of 17 schools scored higher than $50 \%$ in the study's parameters. The study by Adrienne Shnier, a doctoral candidate in health policy and equity at York University in Toronto, Ontario, and colleagues also found that one school, the Northern Ontario School of Medicine, had no policy as of 2011.

"Conflicts of interest are systemic," says Shnier, whose coauthors include Dr. Joel Lexchin, a health-policy professor at York University.

Other schools lost points for various shortcomings, including not barring direct industry compensation to faculty members, allowing faculty to sign on to ghostwritten studies or failing to make conflict-of-interest education a part of the curriculum. Shnier notes that 9 of the 17 Canadian medical schools had no policy on ghostwriting. The University of Western Ontario in London had the most comprehensive policy with a $79 \%$ score.

Shnier thinks all lectures - offered by external experts or faculty — should be free of industry ties. "There are enough independent researchers and independent physicians who are knowledgeable about the topics that are taught in medical schools."

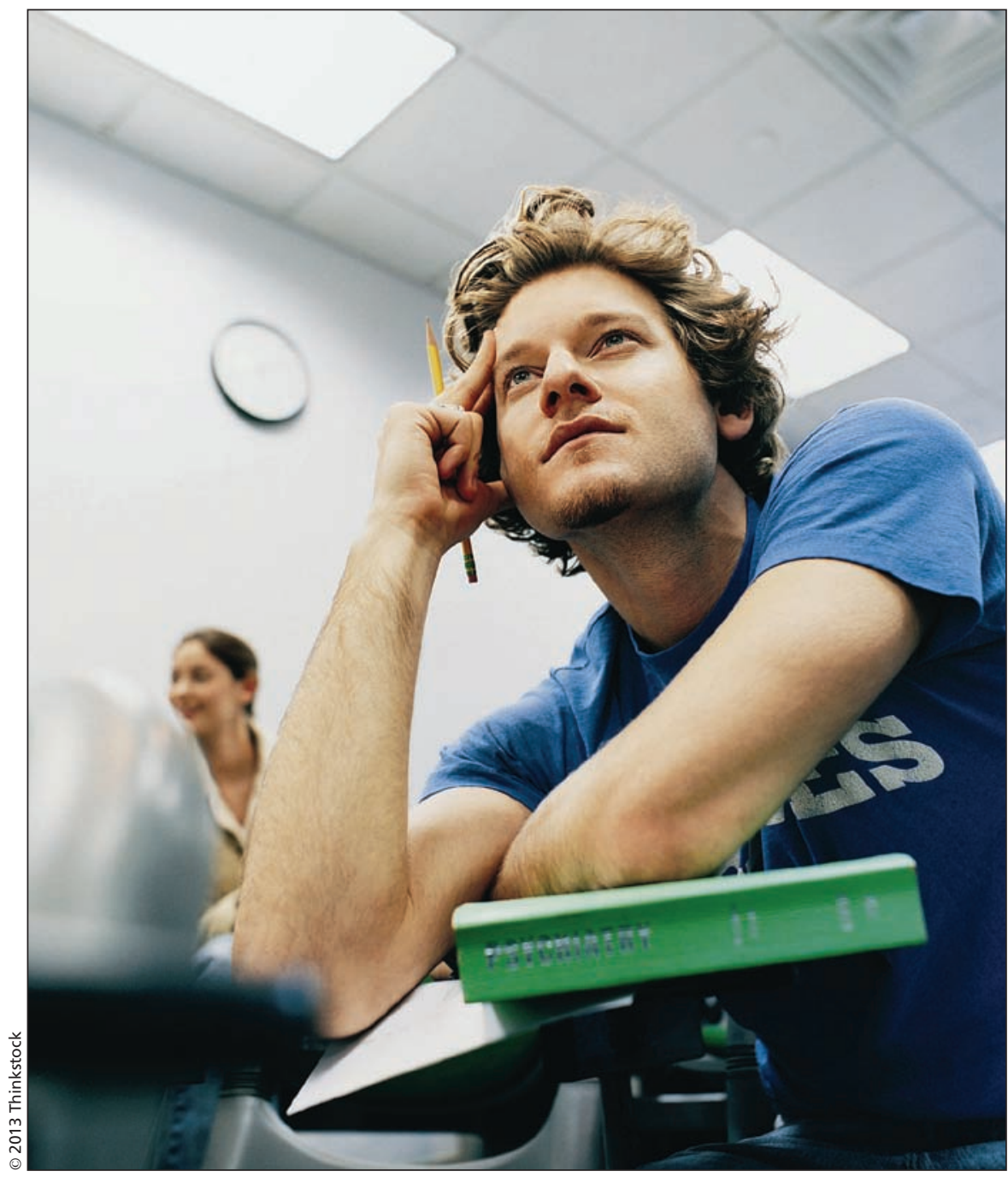

Medical students aren't given enough instruction in the types of conflicts of interest and their implications, warn some physicians.

She adds that "schools could agree to only present evidence that's independent of drug company material," although she recognizes companies would necessarily be the source for clinical trials of new branded drugs.

A second recent publication on conflicts of interest comes from Dr. Navindra Persaud, a family physician at St. Michael's Hospital in Toronto and an associate editor for CMAJ. Persaud, who is also a lecturer at the University of Toronto, openly challenged medical schools' relationships with industry in a recent case study in the Journal of
Medical Ethics ( $\mathrm{J}$ Med Ethics doi: 10.1136/medethics-2013-101343).

It examined a pain-management course offered at the University of Toronto between 2004 and 2010 that Persaud took while a student. For Persaud, the presented slides raised red flags because they seemed to downplay the negative effects of oxycodone and included an alleged direct quote from a 2006 CMAJ article saying placebocontrolled trials showed "strong" and "consistent" evidence that opioids relieve pain and improve function for patients with chronic, noncancer pain. 
The quote doesn't exist in the cited article, however, nor does the original article use the words "strong" and "consistent" to describe the evidence (www.cmaj.ca/lookup/doi/10.1503/cmaj .051528)

In addition, a textbook given to students was published by Purdue Pharma, the maker of Oxycontin, and Persaud found that the lecturer, Dr. Roman Jovey, had received money from Purdue in the past.

Jovey didn't mention his previous Purdue funding in the slide materials, but in an email to CMAJ, he says he verbally disclosed it. He also said his involvement in the week-long course was voluntary, the CMAJ misquote was an "inadvertent error" and that Persaud focused on "a small number of slides," whereas the overall lectures "summarized a practical, clinical approach to pharmacotherapy of pain, including the challenge of using opioids."

In an email statement, Purdue Pharma said the book was "authored by independent medical experts, sponsored by Purdue and endorsed by the Canadian Pain Society" and that "Rx\&D's Code of Ethical Practices has strict guidelines for the pharmaceutical industry's sponsorship of medical education."

The University of Toronto no longer distributes the Purdue textbook and Jovey hasn't taught the pain-management course since 2010. Dr. David McKnight, associate dean of equity and professionalism at the university's faculty of medicine, says these decisions were not because of evidence of actual bias, but because Jovey's relationship with Purdue Pharma meant the lecture had the "potential" for bias.

Meanwhile, the medical school's new February 2013 conflict-of-interest policy states that faculty members should not be members of industry speakers' bureaus and the school has intensified its conflict-of-interest curriculum in recent years.

But curricula in this area still aren't sufficient, says Lynette Reid, professor of bioethics at Dalhousie University's faculty of medicine in Halifax, Nova Scotia. "We talk to students for three hours in first or second year ... you can't expect that to outweigh what they see in practice," says Reid, whose own research found the majority of top cardiologists at Canadian medical schools either participated in industry speakers' bureaus or received honoraria from pharmaceutical companies.

While most schools require faculty to disclose any conflicts, Persaud says disclosure can also lead to complacency. "You start to think that's normal, that most of the people you look up to and want to be like in 10 years receive pharmaceutical support," he says. Additionally, he doesn't think medical students have enough knowledge and experience to differentiate biased from independent information.

Jesse Kancir, president of the Canadian Federation of Medical Students, points out, however, that only $5 \%$ of his lecturers at the University of Toronto have had conflicts of interest to disclose and "it does cause you to question and filter what they say."

Kelly Holloway, a PhD student in sociology at York University who coauthored the PLoS One article, says the most industry influence comes from doctors not bound to university rules: voluntary preceptors. In her interviews with medical students, she's found overexposure to pharmaceutical-sponsored literature in clinics and preceptors' relationships with pharmaceutical reps were more common than pharma involvement in the classroom setting.

Holloway points out such issues will only become more prevalent as medicine is "increasingly corporatized and privatized" and funding to postsecondary education dwindles. Meanwhile, government grants to medical schools may require industry partnership, McKnight points out.

To Persaud, however, decreased funding is no excuse. "I don't think there's any need for pharmaceutical involvement," he says. "Just like the universities manage to find resources to put philosophers in front of philosophy students, medical schools can find the funds to put medical lecturers in front of medical students." - Wendy Glauser, Toronto, Ont.

CMAJ 2013. DOI:10.1503/cmaj.109-4563

\section{More News online}

Discussion with a digital health pioneer: New and emerging digital technologies will improve health care and change the way medical information is gathered, accessed and shared, says Dr. Eric Topol. - Paul Webster, Ottawa, Ont.

Health Canada should license companies that mix drugs, says report: Health Canada should regulate businesses that mix drugs outside of licensed pharmacies, recommends an expert who investigated why 1202 patients, including 40 children, in Ontario and New Brunswick received diluted chemotherapy drugs between February 2012 and March of this year. - Catherine Cross, CMAJ

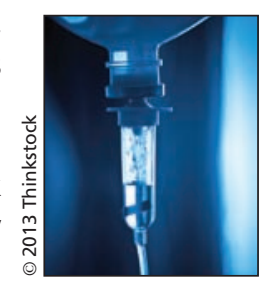

New health minister doesn't mean new regime, say experts: Canada has a new federal health minister: Rona Ambrose. While some Canadian health care advocates have expressed optimism about the new minister, their general outlook on the shuffle is cynical. - Catherine Cross, CMAJ

A chat with Cabinet Minister Dr. Kellie Leitch: She's an MD, an MP and has an MBA. Now 42-year-old pediatric orthopedic surgeon Dr. Kellie Leitch has another title: Cabinet minister. In his recent Cabinet shuffle, Prime Minister Stephen Harper appointed Dr. Kellie Leitch to the positions of minister of labour and minister of status of women. - Roger Collier, CMAJ

CMAJ 2013. DOI:10.1503/cmaj.109-4575 cmaj.ca 